\title{
Comparativa entre modelos turísticos sostenibles vigentes en España y Costa Rica; tomando como referencia la región de Murcia, Cartagena y la región Caribe Sur, Gandoca
}

Comparison between sustainable tourism models in force in Spain and Costa Rica; Taking as reference the region of Murcia, Cartagena and the South Caribbean region, Gandoca

Allan Alexander Cerdas-Monge ${ }^{1}$

Cerdas-Monge, A. Comparativa entre modelos turísticos sostenibles vigentes en España y Costa Rica; tomando como referencia la región de Murcia, Cartagena y la región Caribe Sur, Gandoca. Tecnología en marcha. Edición especial Movilidad Estudiantil 7. Abril, 2020. Pág.78-81.

doi) https://doi.org/10.18845/tm.v33i6.5169 


\title{
Palabras Clave
}

Desarrollo sostenible; turismo sostenible; modelos turísticos; España; Costa Rica.

\section{Resumen}

El turismo representa grandes oportunidades para los comercios turísticos, permitiendo desarrollar la economía de una región en: los factores humanos, políticos, ambientales permite que se desarrolle con gran facilidad. Los ambientes desarrollados por el turismo en la ciudad de Cartagena, España, se logra determinar con el análisis en factores que hacen que una región logre empoderarse con una actividad tan importante, permitiendo enfocar la comparativa con los modelos de la región de Gandoca, Sixaola. La investigación se basa sobre un análisis comparativo entre ambas regiones que permite ver la gran diferencia entre ambas regiones.

\section{Keywords}

Sustainable development; sustainable tourism; tourism models; Spain; Costa Rica.

\begin{abstract}
Tourism represents great opportunities for tourist trade, allowing to develop the economy of a region in: human, political, environmental factors allow it to develop with great ease. The environments developed by tourism in the city of Cartagena, Spain, can be determined with the analysis of factors that make a region able to empower itself with such an important activity, allowing to focus the comparison with the models of the region of Gandoca, Sixaola. The research is based on a comparative analysis between both regions that shows the great difference between the two regions.
\end{abstract}

\section{Introducción}

En España desde los años 70 se ha implantado un modelo de desarrollo turístico de masas fuertemente criticado por su impacto ambiental, debido esto en los últimos años sus políticas turísticas han incluido el concepto de sostenibilidad ambiental, sin embargo, su modelo de desarrollo turístico es el mismo y con una idea muy diferente de sostenibilidad la que tiene Costa Rica.

España ha generado desastres ecológicos por la construcción de hoteles de transnacionales optado por un desarrollo de masas un modelo muy diferente de Costa Rica no se ha desarrollado en la región del Caribe Sur de Costa Rica, para no romper el esquema de sostenibilidad.

Los modelos turísticos entre España y Costa Rica son modelos muy diferentes, la gran demanda turística es un ejemplo de lo que se mencionara, los enfoques turísticos entre estos países son muy grandes. España se caracteriza ser por un destino muy conocido como "turismo de Masa" es esta actividad se caracteriza por ser una actividad demándate y poco sostenible con el ambiente, Costa Rica es todo lo contrario, se caracteriza por ser totalmente sostenible y desarrollar actividades locales. La finalidad de este artículo es presentar una reflexión especialmente entre los modelos turísticos de estas regiones, donde vemos dos panoramas muy diferentes entre Cartagena y Gandoca. 


\section{Desarrollo turísitco y sostenibilidad}

\section{Antecedentes al turismo sostenible}

Antes de explicar los planes llevados a cabo de cara a implantar un turismo más responsable y competitivo en el ámbito nacional e internacional, se hará un breve repaso del desarrollo turístico previo a la preocupación por un turismo sostenible entre España y Costa Rica. Ya que se estaba poniendo en peligro el futuro del turismo, carente de gestión y planificación.

El origen del turismo de masas en España se genera entre 1960 y 1973, donde el número de visitantes pasó de 6.113.255 en el año 1960 a 34.558.943 visitantes en 1973, con tasas anuales de variación superiores al 10\% en la mayoría de sus años. El turismo receptor internacional provenía de Inglaterra y Alemania, en busca de un turismo vacacional en la zona del litoral mediterráneo. Dicho crecimiento acelerado en la demanda provoco un evidente aumento en la construcción para hospedar a dichos turistas en establecimientos hoteleros, campings, apartamentos, etc.... Dando lugar a una importante generación de empleo en la economía española. Todo este desarrollo turístico se llevó a cabo sin la existencia de planes de ordenación territorial ni urbanísticos, a falta de una planificación turística con perspectivas de futuro [1].

Los modelos Turísticos en Costa Rica empezaron entre los años ochenta y noventa con un modelo no muy diferente al de Españas a inicios de los años sesentas, con un modelo de sol y playa a medida que esto ocurría en el país de decide crear a un instituto legal asi lo determinaba Ya desde 1955, por medio de la Ley Orgánica No 1917, se crea el Instituto Costarricense de Turismo (ICT) cuya misión es "promover el desarrollo turístico integral con el fin de mejorar el nivel de vida de los costarricenses, manteniendo el equilibrio entre lo económico, lo social, la protección del ambiente, la cultura y la infraestructura" y tiene como finalidad principal incrementar el turismo en el país [2].

En Región de Murcia cuentan con Espacios de naturales protegidos algunos de ellos se mencionarán a continuación:

- Cañón de los Almadenes.

- Parque Regional Sierra del Carche.

- Parque Regional de la Pila.

- Parque Regional El valle y Carrascoy.

- Parque Regional Sierra Espuña.

- Parque Regional Salinas de San Pedro

- Parque Regional de Calblanque.

- Parque Regional Calnegre y Cabo Cope.

- Reserva Natural Cañaverosa.

- Paisaje Protegido Ajauque y Rambla salada.

- Paisaje Protegido Islas y Espacios del Mar Menor.

Esta información fue emitida por medio del Instituto de Turismo de la Región de Murcia.

En la provincia de Limón contamos con una gran cantidad de áreas protegidas ellas son:

- Refugio de vida silvestre Barra del Colorado. 
- Parque Nacional Tortuguero.

- Parque Nacional Cahuita.

- Reserva Biologica Hitoy Cerere

- Refugio de Vida Silvestre Gandoca-Manzanillo.

Actividades turísticas de la región de Murcia Cartagena.
1. Sol y Playa
2. Religioso
3. Cultural/Mice/Ciudades
4. Senior
5. Náutico
6. Fútbol
7. Golf
8. Naturaleza Y Activo
9. Salud Y Belleza - Médico
10. Gastronómico
11. Enoturismo
12. Camping
13. Cruceros
14. Idiomático

\section{Actividades Turísticas de La Provincia de Limón, Gandoca.}
1. Sol y playa
2. Surf
3. Snorkel
4. Kayaking
5. Buceo
6. Pesca
7. Canopy
8. Cabalgatas
9. Rápidos
10. Cuadraciclo
11. Ciclismo montaña
12. (Instituto Costarricense de Turismo, 2015-2016) 
Las Actividades turísticas entre ambas regiones son muy diferentes con grandes dimensiones del tipo de turista que visita la zona y sus intereses de ocio. La región de Murcia en Cartagena se basa en un modelo de turismo cultural, comercio, histórico un modelo muy interesante para los turistas de la unión europea y continentes cercanos. Por otra parte, el turismo que la zona de Limón en Gandoca ofrece es un turismo rural, ecoturismo, sol y mar de una forma sostenible sin modelos de hoteles de grandes cadenas como lo son NH, RIU, BARCELÓ, IBERIOSTAR, EUROSTAR entre otros hoteles. La comunidad de Gandoca tiene lo que son posadas turísticas, realizadas por pequeños empresarios pymes que mediante el modelo de turismo sostenible se auto sustentan de las ganancias de los visitantes que quieren un entorno muy natural y un modelo totalmente diferente al de España que viene siendo un modelo generado por empresarios poderos económicamente.

El Plan Integral de Calidad y Turismo Español (PICTE) fue desarrollado entre los años 20002006, donde las empresas y servicios turísticos ejercen acciones estableciendo estándares de calidad. En esta etapa el turismo se recuperaba de la mala imagen dada en periodos anteriores y coincide el periodo de convergencia hacia los programas e iniciativas de la UE [3] [1].

\section{Conclusiones}

Después de la reflexión a que condujo esta investigación, se puede afirmar que ambos países tienen en claro la importancia de la actividad turística como parte del desarrollo sostenible y su efecto de amortiguar los impactos ambientales actuales, los modelos de turismo son muy diferentes y cabe decir que Costa Rica tiene mucha más ventaja en temas ambientales sostenibles que España esto porque no se ha hecho una sobre explotación de recursos naturales, como de igual forma España tiene más desarrollo económico que Costa Rica, esto por la cantidad de turismo que acaparan, mediante planes estratégicos y un plan de ordenamiento territorial.

El turismo en la región de Murcia, Cartagena es muy activo y dinámico gracias la gran cantidad de embarcaciones de cruceros que llegan a lugar como punto de destino, las excelente infraestructura en los puertos, su gran cantidad de museos históricos, la gran gastronomía. Pero la persistencia en el tiempo de la actividad turística depende, en gran parte, por una adecuada planificación sin perjudicar a los ámbitos económicos, sociales y ambientales en el largo plazo. Los cambios en la demanda, por un turista más concienciado ambiental y culturalmente, ponen en auge la búsqueda de destinos turísticos donde exista cierta belleza paisajística y se disfrute de la cultura y tradiciones de la zona. Estos cambios están dejando obsoletas las zonas de sol y playa masificadas que predominan en el levante español, debido en gran parte al desarrollo urbanístico descontrolado. La Región de Murcia lo refleja mayormente en la zona de la Manga del Mar Menor, donde las encuestas de satisfacción a los turistas de esta zona valoran con menor puntuación las variables relacionadas con los espacios verdes, la falta de actividades culturales y el exceso de tráfico en épocas estivales de verano.

Personalmente opino que para que un modelo turístico sea exitoso debería empezar por los gobiernos locales para que se haga un planteamiento, ordenamiento de los esquemas turístico en una ciudad o pueblo es la mejor forma de tener un modelo éxito de turismo de igual forma no se debe olvidar que toda practica turística debe ser responsable para poder ejercerse. Las dimensiones entre Costa Rica y España son muy grande y el turismo son totalmente diferentes pero hay que destacar que ambos países empezaron su modelo turístico con el famoso sol y playa y además que Costa Rica logro ir cambiando su modelo durante los años y ahora los países como es España están en camino del ese cambio sostenible. 


\section{Agradecimientos}

El autor agradece a las Vicerrectorías de Investigación y Docencia del Instituto Tecnológico de costa rica que intervinieron para hacer posible la realización de la pasantía. Un agradecimiento Administración Y Dirección De Empresas Universidad Politécnica De Cartagena, Facultad De Ciencias De La Empresa.

\section{Referencias}

[1] J. M. Mompeán (2014-2015). Turismo sostenible y la ordenación del territorio: análisis y conclusiones en la región de Murcia. Murcia, España.

[2] L. D. Alvarado (2009). Evolución e importancia del turismo en Costa Rica. San Jose : Conare.

[3] Instituto Costarricense de Turismo. (2015-2016). Plan Nacional de Turismo Sostenible Costa Rica. 